\title{
Students' perspectives of using cooperative learning in a flipped statistics classroom
}

\author{
Liwen Chen \& Tung-Liang Chen \\ Graduate Institute of Technology Management, Chung-Hua University, Hsinchu, Taiwan \\ Nian-Shing Chen \\ Department of Information Management, National Sun Yat-sen University, Kaohsiung, Taiwan
}

\begin{abstract}
Statistics has been recognised as one of the most anxiety-provoking subjects to learn in the higher education context. Educators have continuously endeavoured to find ways to integrate digital technologies and innovative pedagogies in the classroom to eliminate the fear of statistics. The purpose of this study is to systematically identify students' perspective of using cooperative learning in a flipped statistics classroom by utilising Q-methodology, which is a combination of qualitative and quantitative research methods. Forty-five students who had participated in a 16 week course were interviewed and asked to rank 30 statements according to their relative importance. Three distinctly different factors that represented groups of participants with similar views were extracted. All groups identified cooperative learning as an effective instructional strategy in flipped classrooms. It is concluded that students' concerns were reflected in these multiple perspectives; therefore, individual levels of support should be provided.
\end{abstract}

\section{Introduction}

Statistics has long been recognised as one of the most anxiety-provoking and difficult subjects to learn in the context of higher education (DeVaney, 2010; Onwuegbuzie \& Wilson, 2003; Schmid, 2013; Williams, 2010). Educators and researchers have continuously endeavoured to find ways to integrate digital technologies and innovative pedagogies in the classroom to eliminate the fear and mystery associated with statistics (Schmid, 2013). Recent research indicates that educators have strengthened their commitment to adopt blended learning (BL) in statistics education to motivate and sustain students to learn (Schmid, 2013; Strayer; 2012). BL is defined as a hybrid method that integrates face-to-face and online learning to produce the combined benefits of both instructional strategies (Bonk \& Graham, 2006; Garrison \& Kanuka, 2004; Graham \& Allen, 2009; Halverson, Graham, Spring, Drysdale, \& Henrie, 2014; Graham, Woodfield, \& Harrison, 2013; Lim \& Morris, 2009; Osguthorpe \& Graham, 2003; Tselios, Daskalakis, \& Papadopoulou, 2011), and it is currently expanding rapidly via the use of different technological tools and diverse functions (Halverson et al., 2014; Jones \& Lau, 2010). With the increased availability of BL environments for any course or subject, the use of a flipped classroom design (garnering the name BL) is on the rise in higher educational institutions (Strayer, 2012).

A flipped classroom is a specific type of BL design that requires students to read course materials or view pre-recorded multimedia lectures in out-of-class time, leaving class time to be utilised to provide them with practice, guidance, and feedback to resolve any problems they may have (Davies, Dean, \& Ball, 2013; McLaughlin et al., 2013; McLaughlin et al., 2014; Strayer, 2012). Thus, the flipped classroom approach can be seen as a way to transform the learning of foundational knowledge into out-of-class activities. The class time saved can be used for higher-level learning (viz., to process information with higher levels of cognitive complexity) and individual/team-based problem-solving applications (Bergmann \& Sams, 2012; Critz \& Knight, 2013; Davies et al., 2013; McLaughlin et al., 2013; McLaughlin et al., 2014; Sankey \& Hunt, 2013). Cognitive research particularly indicates that learning is greatly enhanced when learners are required to engage in the application of analysis, evaluation, and creation of higher-level thinking skills, as identified in Bloom's Revised Taxonomy (Ferguson, 2002; Krathwohl, 2002; Mayer, 2002; Pintrich, 2002).

In terms of the use of online technological resources as teaching and learning tools, Garfield (2013) stresses the increasing importance of using well-designed cooperative learning (CL) activities in physical, online, hybrid, or even flipped statistics classrooms. It is widely believed that CL has a positive effect on achievements within the field of statistics education (Giraud, 1997; Keeler \& Steinhorst, 1995; Magel, 1998; Steinhorst \& Keeler, 1995). CL is especially important in the statistics classroom because most statistical work is group work, with statistical results communicated effectively among group members. Instructions 
on statistics should develop students' teamwork and communication skills, even those of non-statistics major students. (Ben-Zvi, 2007). Conceptually, it is acknowledged that there is a need to examine CL in flipped classrooms in statistics education (Strayer, 2012). The recent promotion of the flipped classroom approach by educators and practitioners has led to the publication of a great deal of research regarding this novel pedagogical method (Davies et al., 2013). However, previous research appears to have failed to fully consider the outcome of integrating CL strategies in a flipped statistics classroom; neither has it considered learners' subjective experience and preferences in flipped classrooms or whether the flipped teaching approach is useful in a Chinese context. Therefore, this study takes a Chinese learner's perspective due to the different tendencies between Chinese learners (viz., students in Mainland China, Hong Kong, Singapore, and Taiwan) and their Western counterparts in terms of online education (Zhang, 2013).

The continual growth in the use of this pedagogy and its potential to resolve the barriers and problems in future higher education programmes make it essential to investigate students' perspective of the use of the flipped classroom approach. It is critical to explore students' views during the initial application of this approach in order to understand how best to integrate technologies into the learning process. Therefore, this study is designed to use Q-methodology, which capitalises on the benefits of both quantitative and qualitative methods, to study human subjectivity. The qualitative nature of Q-methodology facilitates an exploration of the diversity of participants' subjective experiences, perspectives, and beliefs. The use of correlation and by-person factor analyses enables the quantitative nature of Q-methodology to capture the essence of participants' feelings about a topic from collective voices, as well as highlighting the subtle differences among those voices.

The aim of this study is to identify and categorise students' opinion of the use of CL strategies and the flipped classroom model in an Introductory Statistics course at a university in Taiwan. The following research questions need to be answered in order to achieve this aim:

1. How many clusters of students share a similar perception of the flipped classroom approach and CL practices?

2. Which specific perceptions of participants' learning experiences provide the basis for distinguishing the clusters that emerge?

An understanding of the current beliefs, attitudes, and values of students toward a flipped classroom will enable university educators and policy-makers to determine how to design, develop, and implement this model to enhance students' learning experience. According to the findings of this research, it is important to better understand how flipped statistics classrooms are perceived by university students in Taiwan. The study is expected to provide a unique insight into how many kinds of students there are, how they can be categorised by their type, and the particular variables that best distinguish different kinds of students.

This paper is structured as follows: (1) The theoretical and empirical background of the study is presented in the first part; (2) The second part contains a review of the relevant existing literature; (3) Details of the methodological approach are provided in the third part; (4) The results of the research are presented in the fourth part; and (5) the fifth part consists of a discussion of the results. The limitations of the study are also addressed in this part and some recommendations are made for further research in this field based on those limitations before concluding the study.

\section{Literature review}

Existing literature related to the outcomes of implementing flipped classrooms in higher education and the effect of using CL in statistics education in traditional classrooms, online classrooms, and flipped classrooms is reviewed below.

\section{Implementing a flipped classroom approach in higher education}

Much attention has been paid to the implementation of a flipped classroom approach in various educational institutions (e.g., online resources, high schools, colleges, and universities) (Bergmann \& Sams, 2012; Chen, Wang, Kinshuk, \& Chen, 2014; Davies et al., 2013; Sankey \& Hunt, 2013). There is a growing body of evidence across a wide range of disciplines, including pharmacology, physiology, nursing, physics, 
mathematics, and business, which indicates that the use of flipped instruction generates a positive outcome (Butt, 2014; Critz \& Knight, 2013; Deslauriers, Schelew, \& Wieman, 2011; Fulton, 2012; Herreid \& Schiller, 2013; McLaughlin et al., 2013; McLaughlin et al., 2014; Missildine, Fountain, Summers, \& Gosselin, 2013; Pierce \& Fox, 2012; Strayer, 2012; Tune, Sturek, \& Basile, 2013). Previous authors propose that the flipped classroom approach enhances students' academic performance (Deslauriers et al., 2011; McLaughlin et al., 2014; Missildine et al., 2013; Pierce \& Fox, 2012; Tune et al., 2013), fosters class attendance (Deslauriers et al., 2011; McLaughlin et al., 2014), improves their engagement (Deslauriers et al., 2011; McLaughlin et al., 2013; McLaughlin et al., 2014), and cultivates a positive attitude toward the course in which it is applied (Deslauriers et al., 2011; McLaughlin et al., 2013; McLaughlin et al., 2014; Pierce \& Fox, 2012). However, some potentially negative effects have also been found within certain subjects in higher educational institutions, with Strayer (2012) arguing that students in a flipped introductory statistics class were less satisfied with the way in which the classroom structure orientated them to the learning tasks. Although the flipped classroom approach sounds promising, recent research indicates certain challenges that diminish the success of the initial implementation when teaching statistics.

\section{Using cooperative learning in statistics education}

A considerable amount of research has been devoted to facilitating CL in traditional, online, or BL classrooms to improve students' learning of statistics. Today, CL itself is hardly a novel idea, since its benefits are widely known. CL refers to a particular set of structured, team-based group activities that are prescribed by the instructor, whereby team members are formally accountable, not only for their own learning, but also that of the group. It emphasises small teams using a variety of learning activities to both improve their understanding of a subject and acquire social awareness. Slavin (1995) suggests four theoretical perspectives related to Vygotsky's (1978) social learning theory that can explain the didactic advantages of CL, namely, motivation, social cohesion, development, and cognitive elaboration. In this model, individuals' competitive behaviour is discouraged in favour of cooperative group-centred learning. Many researchers stress that CL helps to attain both academic and social goals (Gillies \& Boyle, 2010; Gillies \& Boyle, 2011; Shih, 2011; Thurston, et al., 2010). Meanwhile, Gillies and Boyle (2010) identify three issues to be carefully considered when implementing CL, namely, students' socialisation during group activities, time management, and the preparation required by teachers.

Apart from the successful implementation of CL in various course subjects, previous studies of statistics education also suggest that cooperative group learning may enhance students' involvement in learning, develop and improve their skills when working with others (Garfield, 1993), increase completion rates, improve students' performance levels in tests (Giraud, 1997; Keeler \& Steinhorst, 1995; Magel, 1998; Steinhorst \& Keeler, 1995), enhance their retention of course material (Keeler \& Steinhorst, 1995), and improve their attitude toward both the course and statistics in general (Keeler \& Steinhorst, 1995; Steinhorst \& Keeler, 1995). Previous researchers have found that CL is useful in a traditional statistics classroom (Garfield, 1993; Garfield, 2013); however, Krause, Stark, and Mandl (2009) suggest that using CL in an eLearning environment does not generate good learning outcomes in statistics education. Nevertheless, in a recent study, Garfield (2013) restated that well-designed CL enhances students' communication, teamwork, and problem-solving skills, whether in class, outside class, or even in online classes. Interestingly, current research indicates that students in a flipped statistics classroom are more open to CL and innovative teaching methods than those in a traditional classroom (Strayer, 2012).

\section{Methodology}

The above literature provides educators with useful insights into the potential of flipped classrooms and cooperative learning. It reveals that, although a substantial amount of research has been devoted to CL, much less attention has been paid to exploring the impact of integrating technology and CL to a flipped statistics classroom. A Q-methodology approach is selected for this particular study to achieve the research objectives and identify participants' unique and common viewpoints. 


\section{Flipped classroom implementation}

The authors of this study were involved in this course as participant observers, instructors, and curriculum designers. Forty-five Taiwanese students (25 male and 20 female) were recruited to participate in a 16 week training programme, an introductory statistics course, at a university in Hsinchu. They were all undergraduate students who had majored in Technology Management, and this was an elective course offered by the College of Management. They voluntarily registered for this course, which consisted of three 1hour sessions per week. It is important to note that convenience sampling was applied to this study, since it is commonly used to recruit participants in Q-methodology (Kalof, 1998). All the students, whose ages ranged from 20 to 22 years, had successfully completed a prerequisite Foundation of Statistics course prior to enrolling for this higher-level course. Since cooperative learning was used as pedagogical practice on this course, three to four students were assigned to each team and involved in segmented missions in the physical classroom. The participants contributed to one another's mastery of various course topics by discussing materials and supporting their group members. Twelve teams were formed and the course was designed as described below.

Firstly, text-based lecture notes and pre-recorded multimedia micro-lectures (four to five micro-lectures of 15 to 20 minutes) were assigned to each class. The contents of this course included sampling, estimation, test of hypothesis, chi-square test, analysis of variance, and regression analysis. These were also presented using an e-learning system as an online resource for students at the university. Secondly, students were required to view pre-recorded multimedia lectures and read lecture notes outside the class times, and were given an individual assessment test before each class, in which they had to answer ten multiple choice questions and five short essay questions. Thirdly, team members spent 40 minutes comparing their responses in their individual assessment tests to agree a team response at the beginning of each class. After comparing the group responses, the teacher reviewed common misconceptions and summarised key concepts during class time. Fourthly, the small groups spent an hour completing team-based short essay questions or case studies with more complex application problems in the physical classroom. The teacher moved around the classroom to provide assistance when needed. At the end of each class, the teacher reviewed the group answers, providing clarification and feedback during class time. Finally, a mid-term exam was held during the 9th week of the course, with the final exam administered during the 16th week. The final score was evaluated based on the results of individual assessment tests, group assessment tests, the mid-term exam, and the final exam.

\section{Research procedure}

Q-methodology, a quantitative analysis of subjective data, was employed for this study and used to generate new ideas and hypotheses, rather than testing existing hypotheses. Q-methodology is rooted in Spearman's factor analysis and used to identify opinion clusters among participants, who inject statements with their own understanding. Q-methodology studies are appropriate when a researcher seeks to identify groups of participants with different perceptions. It especially encourages the identification of what means the most and the least to a participant in the context of a flipped classroom. The research stages of this Qmethodology were as follows: (1) development of a research instrument, (2) data collection, and (3) data analysis (see Figure 1). 


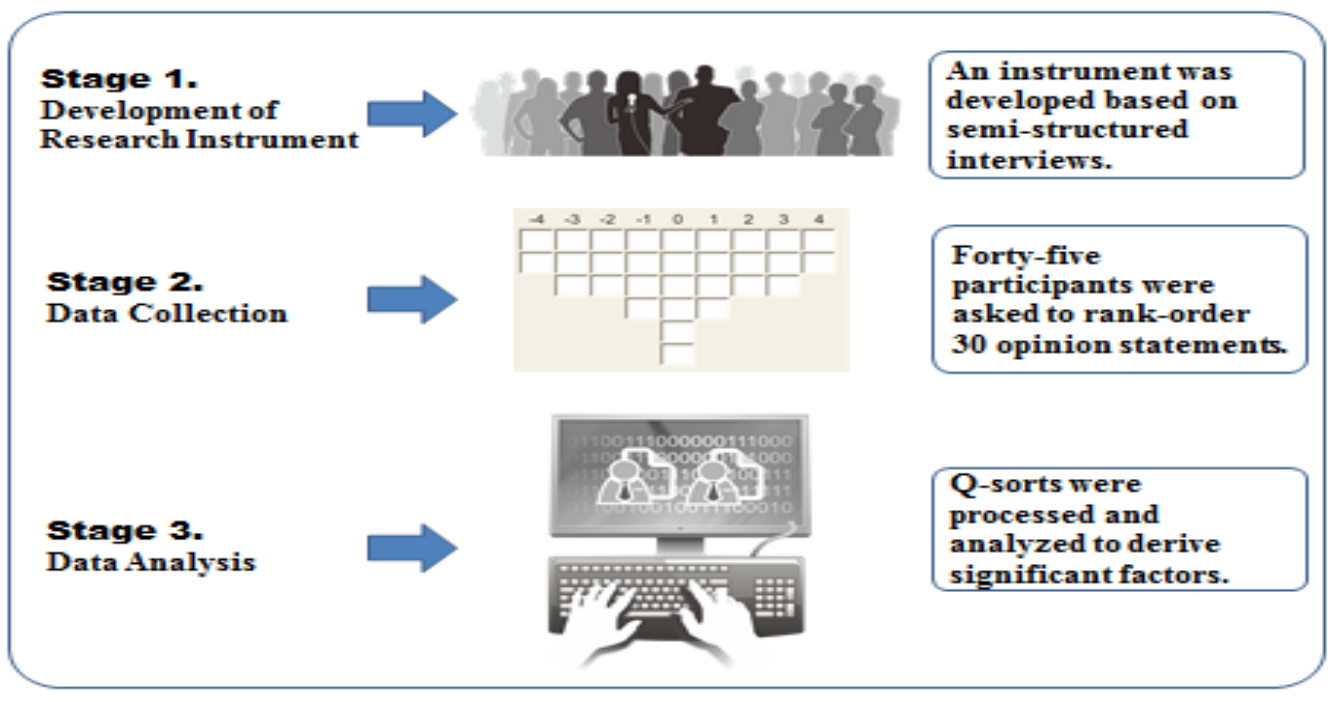

Figure 1. Q-methodology research stages

Stage one: Development of the research instrument

Semi-structured interviews were conducted with all of the students one week after they completed the training programme to understand their perspective of the topic. Opinion statements, called concourse, were collected through group and personal interviews for this study. Concourse is usually collected from readymade items (e.g., essays, pictures, publications, paintings, photographs, and art pieces) or naturalistic sources (interviews or group discussions) (Brown, 1996; McKeown \& Thomas, 1988; Valenta \& Wigger, 1997). In this study, opinion statements were collected from the students during the interviews rather than using ready-made items. It is important to note that Q-statements (i.e., the opinion statements of the research instrument) in Q-methodology are selected as carefully as the participant selection is conducted in any other scientific method (Brown, 1996; McKeown \& Thomas, 1988; Valenta \& Wigger, 1997). A content analysis was used to select the final Q-statements from the concourse with the help of two experts in the subject matter, who were asked to read through the original and final sets of statements and comment on them to help to reduce the opinion items to a manageable number and ensure that the selected Q-statements comprehensively represented the discussion about the flipped classroom approach. After conducting the content analysis, a stratified sampling method was used to select the final set of Q-statements, which were then categorised into three domains, namely, teaching and learning issues, technological issues, and social and communication issues. A sample of 30 statements representing key ideas from each domain was developed as the basis of the research instrument (see Figure 2).

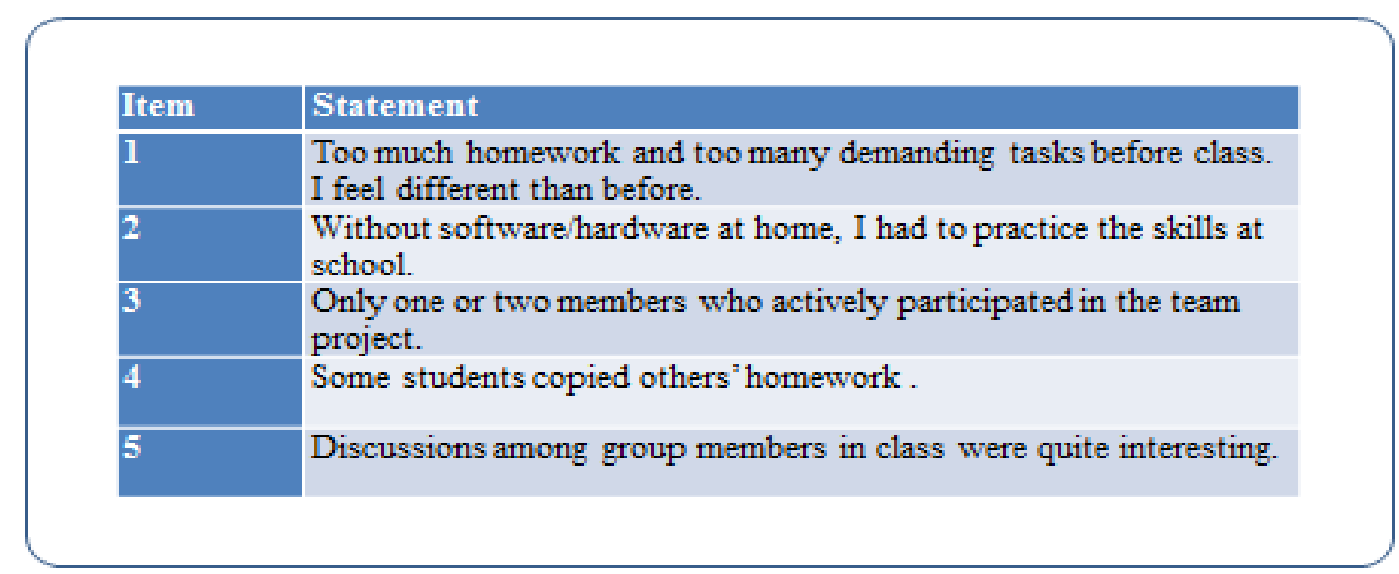

Figure 2. Examples of the statements

As a result, the format of the Q-sort design consisted of 9 piles (-4 through +4 , with frequencies 2-3-3-4-64-3-3-2). The design regulated the exact number of statements a participant was able to put into each pile in the continuum from mostly agree $(+4)$ to mostly disagree (-4). More statements could be placed into the 
middle area and fewer statements at both ends (i.e., left: mostly disagree-middle: neutral-right: mostly agree). The sorting answer sheet used in this study forced the Q-sort into the shape of a quasi-normal distribution (see Figure 3). Pilot testing was conducted with four volunteers who participated in the first semi-structured interview, with only minor changes needing to be made to clarify some Q-statements.

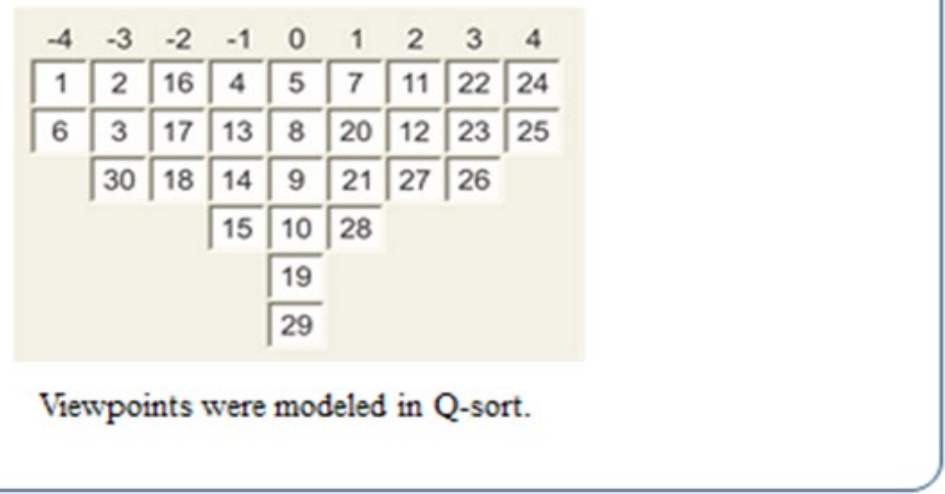

Figure 3. An example of a completed Q-sort

Stage two: Data collection

According to the sorting instructions given by the researchers, the participants were asked to rank 30 opinion statements about the flipped classroom approach from the most to the least favourable (usually from most agreeable to most disagreeable). Each student ranked the 30 statements along a continuum ranging from '-4' (most disagreeable) to '+4' (most agreeable) on the sorting answer sheet (see Figure 3). Therefore, each trainee carried out the Q-sorting with the same Q-sample. Sorting instructions and an answer sheet were provided to clarify the procedure. The final opinion statements and the Sorting Answer Sheet (see Appendix A) were distributed to the respondents, together with the Sorting Instructions (see Appendix B). The total time taken to administer the instrument was less than 30 minutes. Participants operationally generated the classifications of the Q-statements as research data. The Q-sorting operation was subjective in that each participant ranked the opinion statements according to his/her personal standpoint; therefore, each participant's Q-sort reflected his/her perspective of the topic (Brown, 1993, 1994, 1996).

Stage three: Data analysis

PQMethod (version 2.11) statistical software was used to analyse the data. This facilitates the data entry of the Q-sorts, computes the inter-correlation among students' responses, and generates several orthogonal (independent) factors (McKeown \& Thomas, 1988; Valenta \& Wigger, 1997). Unlike R-methodology (a conventional factor analysis) that correlates variables to identify relationships between objective variables for a number of individuals, Q-methodology correlates whole individuals to identify patterns in their subjective perspective; hence, people are correlated in Q-methodology, but not traits or items as in Rmethodology. Various factor rotation and statistical procedure methods can be used to safeguard factor reliability in Q-methodology. Correlation, centroid factor analysis, and judgmental rotation (i.e., hand rotation) are employed to derive the significant factors in this study.

\section{Results}

The use of PQMethod software enabled this study to reveal the students' statement scores by factor/opinion types (see Tables 1 and 2). Factors that represented groups of participants with similar perceptions were extracted, thus uncovering the different patterns of thought expressed in their subjective views. The analysis of the students' Q-sorts yielded three distinctive factor groups (see Table 1). Thirty-nine (86.7\%) of the 45 students' Q-sorts were divided into three operant factors using the centroid method and judgmental rotation for factor extraction. Four of the remaining six Q-sorts were not considered to be statistically significant, with loadings of less than 0.36 on these three factors, with another two being confounded; that is, loading significantly on more than one factor. PQMethod software offers two methods of factor extraction: (1) the principal component method and (2) the centroid method. Most Q-methodologists use the centroid method 
for their studies. Interested readers are referred to Brown (1993, 1994, 1996), and McKeown and Thomas (1988) for further theoretical issues and guidelines.

When addressing the two original research questions in order to achieve the research aim, the results indicate the following: (1) the 3-factor structure (i.e., Factor A, B, and C) suggests there were three types of students with regard to flipped classroom practices (see Table 2); and (2) the distinguishing statements help to define and explain the uniqueness of each factor, as the factor scores were used to further represent the characteristics of each cluster (see Table 2), with the first factor describing hesitant and limited computer access cooperative students (Factor A), the second factor describing hesitant and classroom behaviour-concerned cooperative students (Factor B), and the third factor describing full-range adoptive students (Factor C). These three specific factors were named based on comparing and contrasting the three sets of distinguishing statements (see Table 2). All the authors discussed their thoughts about these items, particularly distinguishing one factor from the others. The factors were distinguished by the ranking of items. Those placed in the most important (viz., +3 and +4 ) and the least important (viz., -3 and -4 ) columns were considered to be distinguishing items in this study, and the researchers assigned a name to each factor based on a group consensus. In other words, a factor was labelled because it was evident in the rankings of the distinguishing items. The overall pattern of the statements helped to understand the views that discriminated the clusters of students (Stellefson, Hanik, Chaney, \& Tennant, 2012). It should be noted that 18 of the students (46.1\%) had Q-sorts that identified them as hesitant and limited computer access cooperators. Factor B, identified as the hesitant and classroom behaviour-concerned co-operators, contained 15 Q-sorts (38.5\%), while the remaining 6 Q-sorts (15.4\%) were in Factor C, full-range adopters. The factor loadings by participant and opinion type are listed in Table 1.

\section{Factor A: Hesitant and limited computer access co-operators}

Eighteen students in this group, comprising 10 males and 8 females, loaded significantly on this factor. These students strongly stated that they had no access to computer/software at home and had to practice the skills at school ( +4 , see Table 2$)$. They also worried that, when they watched lecture videos online, they were unable to ask the teacher any questions $(+3)$. Compared with their prior experience, this group expressed strong concern that they felt uncomfortable because of the demanding tasks and homework before class $(+4)$. Overall, this group probably does not value the flipped classroom approach as a better teaching and learning approach.

Nevertheless, this group did value the fact that, because of the team system, they could ask team members for help with problems they were otherwise unable to resolve themselves (+3). They felt positive about the use of discussion groups in class (+3) and believed that students who had grasped the concepts voluntarily taught others who found it difficult to understand the material $(+3)$. They felt positive in terms of the Internet speed and quality of the pre-recorded video lectures. Factor A students also considered it unfair to give one grade to the entire group rather than separate grades to individual students, especially when all students did not make an equal contribution (+2). However, they had a negative attitude toward the issue of whether attendance should be taken by the teacher on a weekly basis (-3). They also strongly disagreed with the statements: "The slow Internet speeds severely undermined the effectiveness of pre-recorded video lectures (-4)", "I felt I could learn everything I needed from the class videos. There was no need to attend class or participate in group-discussion activities (-4)", and "I took notes while watching the pre-recorded multimedia videos (-3)". 
Table 1

Factor loadings by participant and opinion type $(*)$

\begin{tabular}{|c|c|c|c|}
\hline ID & Factor A & Factor B & Factor C \\
\hline 3 & 55 & & \\
\hline 4 & 59 & & \\
\hline 5 & 61 & & \\
\hline 9 & 57 & & \\
\hline 10 & 51 & & \\
\hline 16 & 36 & & \\
\hline 17 & 64 & & \\
\hline 23 & 78 & & \\
\hline 25 & 88 & & \\
\hline 27 & 79 & & \\
\hline 28 & 70 & & \\
\hline 31 & 56 & & \\
\hline 32 & 60 & & \\
\hline 33 & 62 & & \\
\hline 37 & 53 & & \\
\hline 40 & 59 & & \\
\hline 41 & 62 & & \\
\hline 44 & 55 & & \\
\hline 1 & & 63 & \\
\hline 7 & & 72 & \\
\hline 8 & & 37 & \\
\hline 14 & & 63 & \\
\hline 18 & & 49 & \\
\hline 19 & & 68 & \\
\hline 20 & & 56 & \\
\hline 21 & & 73 & \\
\hline 22 & & 38 & \\
\hline 30 & & 68 & \\
\hline 34 & & 73 & \\
\hline 35 & & 72 & \\
\hline 36 & & 74 & \\
\hline 43 & & 57 & \\
\hline 45 & & 41 & \\
\hline 2 & & & 47 \\
\hline 6 & & & 75 \\
\hline 11 & & & 73 \\
\hline 13 & & & -43 \\
\hline 26 & & & 54 \\
\hline 29 & & & 62 \\
\hline
\end{tabular}

$(*)$ only significant loadings shown $(\mathrm{p}<.01)$; decimals omitted

\section{Factor B: Hesitant and classroom behaviour-concerned co-operators}

Fifteen of the 45 students loaded on the second factor. This group consisted of 8 males and 7 females. They believed that discussions among group members in class were quite interesting $(+3)$, but they could be improved by taking attendance because some students tended to skip classes (+3) or surfed the Internet $(+4)$ because they knew that the lectures would be posted online. Although they watched the recorded lectures on a weekly basis, they still considered it necessary to attend class and participate in group discussions (4). These students worried that, when they watched lecture videos online, they were unable to ask the teacher any questions (+3). This group also found it difficult to manage the demanding homework and tasks before class (+4). In summary, this group may not value the flipped classroom approach as a better teaching and learning approach. The striking difference between the perception of Group A and Group B participants is that Group A participants explained that they did not have access to hardware/software at home and thus had to practice the skills at school (+4), while Group B participants perceived this to be a problem in the 
opposite way (-3). They disagreed with the statements: "I did not watch the recorded lectures on a weekly basis and opted to review the materials only in preparation for the mid-term and final exams (-4)," "I took notes while watching the pre-recorded multimedia videos (-4)," and "This approach allowed each student to learn at their own pace $(-3)$."

\section{Factor C: Full-range adopters}

Q-Sorts from 6 participants, consisting of 4 males and 2 females, loaded significantly on this factor, which was bipolar, with one student loading negatively (see Table 1). Only the viewpoints articulated by the positively loaded participants will be explained in the following factor summary. Those without hardware/software at home $(+1)$ in this profile exhibited a generally positive attitude toward using cooperative learning strategies and flipped teaching methods. They strongly considered that a flipped classroom was better than the traditional teaching method and believed that this helped to enhance their critical-thinking and problem-solving skills (+4).

Full-range adopters also strongly believed that, because they watched the pre-recorded multimedia videos prior to attending classes, the learning contents were easier for them to understand $(+3)$. In addition, they felt that the group discussions were quite interesting and helped to establish a group consensus (+3). Some classmates interacted outside their assigned groups by sharing the course content and their thoughts with classmates in other groups (+3). They disagreed with the statements "I felt I could learn everything I needed from the class video. There was no need to attend class or participate in group-discussion activities (-4),” and "I took notes while watching the pre-recorded multimedia videos (-3)." In contrast with the other two groups, full-range adopters did not feel that this approach generated too much homework (-4) and did not believe that attendance needed to be taken, even though some students skipped classes because they knew that the lectures were posted online (-3).

Table 2

Students' statement scores by factor/opinion types

\begin{tabular}{lr}
\hline Factor statements & Rankings (*) \\
\hline
\end{tabular}

\section{Factor A: Hesitant and limited computer access co-operators}

1 Too much homework and too many demanding tasks before class. I feel different than I did before.

2 Without software/hardware at home, I had to practice the skills at school.

A $\quad$ B $\quad$ C

5 Discussions among group members in class were quite interesting.

8 When I watched lecture videos online, I was unable to ask the teacher questions when they arose.

11 Because of the team system, I was able to ask team members for help with problems I couldn't resolve myself. Using discussion groups in class allowed students who grasped the concepts to teach those who were finding it difficult to understand the material.

13 I consider it to be unfair to give one grade to the entire group rather than separate grades to individual students, especially when all students did not make an equal contribution.

18 The slow Internet speeds severely undermined the effectiveness of pre-recorded $\quad \begin{array}{llll}-4 & -1 & -2\end{array}$ video lectures.

30 I felt I could learn everything I needed from the class videos. There was no need $\quad-4 \quad-4 \quad-4$ to attend class or participate in group-discussion activities. 
$7 \quad$ Attendance should be taken because some students skipped classes because they $\quad \begin{array}{llll}-3 & 3 & -3\end{array}$ knew that lectures were posted online.

26 I took notes while watching the pre-recorded multimedia videos.

$-3 \quad-3 \quad-3$

Factor B: Hesitant and classroom behaviour-concerned co-operators

1 Too much homework and too many demanding tasks before class. I feel

$\begin{array}{lll}4 & 4 & -4\end{array}$
different than I did before.

17 Some students surfed the Internet during classes.

$\begin{array}{lll}-1 & 4 & 0 \\ -3 & 3 & -3\end{array}$

7 Attendance should be taken because some students skipped classes since they knew that lectures were posted online.

5 Discussions among group members in class were quite interesting.

8 When I watched lecture videos online, I was unable to ask the teacher questions when they arose.

25 I did not watch the recorded lectures on a weekly basis and opted to review the $\quad \begin{array}{llll}-2 & -4 & 0\end{array}$ materials only in preparation for the mid-term and final exams.

30 I felt I could learn everything I needed from the class videos. There was no need $\quad-4 \quad-4 \quad-4$ to attend class or participate in group-discussion activities.

2 Without software/hardware at home, I had to practice the skills at school. $\quad 4 \quad-3 \quad 1$

26 I took notes while watching the pre-recorded multimedia videos.

$-3 \quad-3 \quad-3$

27 This approach allowed each student to learn at their own pace.

$-1 \quad-3 \quad 2$

\section{Factor C: Full-range adopters}

24 This approach improved my critical-thinking and problem-solving skills.

$\begin{array}{lll}-2 & -2 & 4\end{array}$

28 This flipped classroom approach is better than the traditional teaching method.

5 Discussions among group members in class were quite interesting.

$\begin{array}{lll}-2 & -1 & 4\end{array}$

12 Videos shown by the trainer made it easy for students to understand the learning materials.

16 Group discussions helped to establish a group consensus. Some classmates interacted outside their assigned groups to share the course content and their thoughts with classmates in other groups.

30 I felt I could learn everything I needed from the class video. There was no need $\quad \begin{array}{llll}-4 & -4 & -4\end{array}$ to attend class or participate in group-discussion activities.

1 Too much homework and too many demanding tasks before class. I feel different than I did before.

7 Attendance should be taken because some students skipped classes since they $\quad \begin{array}{llll}-3 & 3 & -3\end{array}$ knew that lectures were posted online.

26 I took notes while watching the pre-recorded multimedia videos.

$\begin{array}{lll}3 & 3 & 3\end{array}$

$1 \quad 1 \quad 3$

* Item rankings: -4 - most unimportant in this sample; 0 - ambivalent; +4 - most important in this sample

\section{Consensus statements}

Taking the analysis as a whole, the results reveal several statements with which the three groups equally agreed or disagreed. Although all three groups had different viewpoints on a number of aspects of this 
pedagogy, there was consensus on several statements (see Table 3). Consensus statements (i.e., those not distinguishing between any pair of factors) among the three groups were Statements 5, 11, 19, 26, and 30 (see Table 3).

Table 3

Consensus statements between Factors A, B, and $C$

\begin{tabular}{|c|c|c|c|c|}
\hline \multicolumn{2}{|c|}{ Factor statements } & \multicolumn{3}{|c|}{ Rankings (*) } \\
\hline & & A & $\mathrm{B}$ & $\mathrm{C}$ \\
\hline 5 & Discussions among group members in class were quite interesting. & 3 & 3 & 3 \\
\hline 11 & $\begin{array}{l}\text { Because of the team system, I was able to ask team members for help with things } \\
\text { I couldn't resolve myself. Using discussion groups in class allowed students who } \\
\text { grasped the concepts to teach those who were having difficulties understanding } \\
\text { the material. }\end{array}$ & 3 & 2 & 2 \\
\hline 19 & $\begin{array}{l}\text { My midterm/final exam scores improved because of the video teaching and group } \\
\text { discussion program. }\end{array}$ & -1 & -1 & -1 \\
\hline 26 & I took notes while watching the pre-recorded multimedia videos. & -3 & -3 & -3 \\
\hline 30 & $\begin{array}{l}\text { I felt I could learn everything I needed from the class video. There was no need to } \\
\text { attend class or participate in group-discussion activities. }\end{array}$ & -4 & -4 & -4 \\
\hline
\end{tabular}

* Item rankings: -4 - most unimportant in this sample; 0 - ambivalent; +4 - most important in this sample

The participants in groups A, B, and C strongly agreed with Statements 5 and 11: "Discussions among group members in class were quite interesting (+3)," "Because of the team system, I could ask team members for help with things I couldn't resolve myself.” They also agreed that using discussion groups in class allowed students who grasped the concepts to teach students who were finding it difficult to understand the material (+3 and +2); on the other hand, they disagreed with Statements 19, 26, and 30: "My midterm / final exam scores improved because of the video teaching and group discussion program (-1)," "I took notes while watching the pre-recorded multimedia videos (-3)," "I felt I could learn everything I needed from the class video and didn't need to attend class or participate in group-discussion activities (4)."

\section{Discussion}

An examination of the three types of opinion profiles in this research (hesitant and limited computer access co-operators, hesitant and classroom behaviour-concerned co-operators, and full-range adopters) indicates that these students used different criteria to state their opinion of a flipped classroom. Some students (i.e., Factor C) reacted positively to this novel teaching approach, while others (i.e., Factor A and Factor B) were opposed to a wide range of envisioned uses of the flipped classroom method. Factor B addressed concerns related to students' in-class behaviour (e.g., class attendance and surfing online during classes), while Factor A strongly focused on the difficulties associated with accessing the hardware/software facility. The fact that some of these net generation students (i.e., Factor A and Factor C), also known as digital natives, have no access to technologies or technology-based tools at home cannot be ignored (Statement 2, see Table 2). This challenges the fundamental assumption underpinning the construct of the net generation, namely that university students are the majority of owners and users of technology who have grown up immersed in a digital environment (Kennedy \& Fox, 2013; Lim, Zhao, Tondeur, Chai, \& Tsai, 2013; Prensky, 2001a, 2001b; Tapscott, 1999). According to our data, it is clear that the digital divide is still an issue for Taiwanese university students; however, the lack of an Internet connection or a computer at home does not mean that they are unable to access school computers to watch pre-recorded multimedia lectures and submit their homework digitally. Therefore, this study proposes that university educators need to re-examine the availability and accessibility of the university's technical resources before implementing this novel approach. The promotion of a flipped classroom approach should be recognised at both individual and institutional levels because the success of any flipped classroom implementation not only involves human infrastructure, but also the physical infrastructure of the institution. 
Overall, the students' reflection of their experience of a flipped statistics classroom shows that the instruction guides and pre-recorded learning content were easy to follow. This is contrary to the assertion of George-Palilonis and Filak (2009) that some students often believe video lectures to be boring and static due to the lack of personal contact. Unlike the findings of their qualitative data, the current study found evidence that all the students had a positive attitude toward the pre-recorded instructional videos. In contrast, these findings accord with previous research (cf. Al Nashash \& Gunn, 2013; Cramer, Collins, Snider, \& Fawcett, 2007; von Konsky, Ivins, \& Gribble, 2009) that students consider video lectures to be an effective learning tool. Furthermore, Factors A, B, and C participants considered learning in this environment to be very intense and generally cooperative. Factor $\mathrm{C}$ participants believed that this method offered them an opportunity to interact after class and explore the course issues that they found to be most pressing. This pedagogy may provide an informal venue for them to cooperate with peers through communication and build communities via the sharing of knowledge. While the results indicate that CL fosters students' growth and enables their voices to be heard throughout the process, Factor A students expressed little confidence in the fairness of group work assessment methods. This result reveals that a fairer grading system should be established for class contributions and agreed prior to the first class.

All the students were new to this flipped statistics classroom approach, but they had had at least two years' experience of using BL in other courses. Flipped classroom research is still a relatively new research area, at least from the perspective of instructors' use of BL strategies. Hence, the preliminary findings of this study suggest that most of the participants may not value this innovative approach as an effective teaching and learning approach at this initial stage of change. Factors A and B participants commented that they found it difficult to handle the heavy demands of weekly assignments before class. Some students resisted activities that gave them a greater sense of responsibility in controlling their self-directed learning process. It is probable that Taiwanese university students have been accustomed to the traditional mode of teaching and learning over the past decades and that this may have engendered a passive attitude toward learning. These results closely echo the findings of Cortazzi and Jin (1997) and Branine (2005) that the Chinese culture of learning values explicit and structured ideas with clearly delineated outcomes and collective efforts rather than individuals taking accountability for their own learning. The results of this study suggest that students have become passive listeners because of their foregoing cultural circumstances rather than being engaged learners in class. These findings lead to the belief that proactive measures and evaluation systems should be established to scrutinise and gauge the way in which students' utilise learning content and pre-recorded videos. In this way, learners' autonomy, self-motivation, and initiative will encourage them to develop life-long learning skills.

This Q-study highlights the fact that these students strongly claim that they feel uncertain and alienated when viewing learning videos in the virtual environment. Previous research conducted by Wei, Chen, and Kinshuk (2012) involved students like those in Factor A and B groups, who stressed the importance of a social presence in distance education, as well as interaction in learning. It would have been better if the teacher had provided scaffolding to support learners when they used their out-of-class time to view the prerecorded multimedia lectures. Future work should endeavour to provide synchronous/asynchronous computer-mediated communication (CMC) spaces for learners to eliminate any unnecessary frustration caused by the web-based learning environment. The time and space flexibility of a supportive CMC environment would be able to foster more in-depth independent learning via student-teacher and studentstudent interaction. More precisely, teachers and curriculum designers may need to be re-educated in order to manage in-class/out-of-class time more effectively.

\section{Conclusion}

This study has highlighted some potential areas for further exploration when implementing this novel instruction/learning approach. It has also identified important issues and initial interventions to avoid setbacks when examining these opinion sets. The overall results reveal five important findings, the first of which addresses the original research question one. The second, third, fourth, and fifth findings of this study contribute new knowledge related to the participants' positive, neutral, and negative perspectives of this pedagogy and address the original research question two.

1. Researchers need to be aware that there are distinctive sets of opinions (i.e., Factors A, B, and C) in the flipped statistics classroom, just as there are learners with diverse needs and backgrounds in traditional classroom settings. 
2. Most young adult students (i.e., Factors A and B) may not be ready to take full control of the learning content and learning process; in other words, they may not innately perceive learning as needing active endeavour.

3. According to Factor A participants, the lack of hardware/software infrastructure may be a potential hindrance to implementing flipped classroom programmes.

4. Factor B participants suggested that teachers should give students a sense of preparedness to manage their positive in-class learning behaviour.

5. All the students appreciated the pre-recorded multimedia lectures and noted that CL appeared to be an effective instructional strategy in the flipped classroom setting.

In short, it can be concluded that the perception of the flipped statistics classroom is a multidimensional construct rather than a unitary one; students experience flipped classrooms in various ways and different views exist within individuals and among groups. Students' concerns need to be effectively addressed for an optimal implementation of a flipped classroom, with an adequate provision of individual and tailored levels of support.

\section{Limitations and Recommendations for future research}

Since they were known to each other and to the moderator, the participants' lack of anonymity may have motivated them to withhold vital information when reaching a group consensus. Therefore, the preliminary results should be generalised with caution due to the convenience sampling of a small number of students. Since Q-studies typically use small sample sizes (Brown, 1993; McKeown \& Thomas, 1988; Valenta \& Wigger, 1997), it is imperative that generalisations from the initial findings should not be inaugurated on the numerical distribution, but rather on the validity and implications of the operant subjectivity conveyed.

It is important to note that Q-methodology is not only interested in the subjectivity or subjective communicability involved in a situation, but also in the operant subjectivity of the Q-sorting process (Brown, 1993, 1994, 1996; McKeown \& Thomas, 1988; Valenta \& Wigger, 1997). In fact, data coding and analysis can be one of the greatest threats to trustworthiness in qualitative research. In this study, the researchers attempted to discover patterns/factors emerge from participants' sorting activity rather than via researcher's systematic classification process of categories and themes as in other qualitative methods. The validity of the interpretation of the results relies on the use of factor analysis in extracting the distinguishing statements. For this reason, researcher bias can be minimized or eliminated in Q-methodology than other qualitative approaches (Shinebourne \& Adams, 2007). Overall, Q-methodology demonstrated to be a powerful and unique method to investigating this educational technology research topic.

As with CL, further research is recommended to determine if peer tutoring can be an effective instructional strategy to help and motivate tutees to learn with peers in the class. Research should be conducted to ascertain how to assess students' work in CL. In addition, it is necessary to conduct more extensive research on implementing a flipped classroom approach in various course subjects if definitive claims along these lines are to be made.

It is also important to note that all the participants' ages ranged from 20 to 22; therefore, a further investigation of the way in which age and maturity influence students' reaction toward the course and academic results is needed. Additionally, the question that remains for future research is whether attendance is an important variable in relation to academic performance in a flipped classroom. Studies should also be undertaken to understand how learning styles contribute to the experience of being in a flipped classroom. The Q-statements can be used as the researcher's best initial guess to start in-depth exploratory interviews with selected participants. The findings of this Q-methodology study can also be further elaborated to support hypothesis-testing research. As Rushby (2013) explains, "Innovation is much more complicated, and takes much longer, than is immediately apparent” (p.56). Therefore, it is proposed that a longitudinal cross-cultural research should be undertaken to increase the understanding of learners' motivational behaviour and the motivating factors in the context of flipped statistics classrooms.

\section{Acknowledgement}


This research was funded by Contract NSC 101-2511-S-216-003 and NSC102-2511-S-216-003 from National Science Council, Taiwan, R.O.C.

\section{References}

Al Nashash, H., \& Gunn, C. (2013). Lecture capture in engineering classes: Bridging gaps and enhancing learning. Educational Technology \& Society, 16(1), 69-78.

Ben-Zvi, D. (2007). Using wiki to promote collaborative learning in statistics education. Technology Innovations in Statistics Education, 1(1). Retrieved from http://www.escholarship.org/uc/item/6jv107c7

Bergmann, J., \& Sams, A. (2012). Flip your classroom: Reach every student in every class every day. Washington, DC, WA: International Society for Technology in Education.

Bonk, C. J., \& Graham, C. R. (2006). The handbook of blended learning environments: Global perspectives, local designs. San Francisco, CA: Jossey-Bass/Pfeiffer.

Branine, M. (2005). Cross-cultural training of managers: An evaluation of a management development programme for Chinese managers. Journal of Management Development, 24(5), 459-472. doi.org/10.1108/02621710510598463

Brown, S. R. (1993). A primer on Q methodology. Operant Subjectivity, 16(3/4), 91-138.

Brown, S. R. (1994). Q methodology as the foundation for a science of subjectivity. Operant Subjectivity, 18(1/2), 1-16.

Brown, S. R. (1996). Q methodology and qualitative research. Qualitative Health Research, 6(4), 561567. doi.org/10.1177/104973239600600408

Butt, A. (2014). Student views on the use of a flipped classroom approach: Evidence from Australia. Business Education \& Accreditation, 6(1), 33-43.

Chen, Y., Wang, Y., Kinshuk, \& Chen, N. S. (2014). Is FLIP enough? Or should we use the FLIPPED model instead? Computers \& Education, 79, 16-27. doi.org/10.1016/j.compedu.2014.07.004

Cortazzi, M., \& Jin, L. (1997). Communication for learning across cultures. In D. McNamara, \& R. Harris (Eds.), Overseas students in higher education: Issues in teaching and learning (pp. 76-90). London: Routledge.

Cramer, K. M., Collins, K. R., Snider, D., \& Fawcett, G. (2007). The virtual lecture hall: Utilisation, effectiveness and student perceptions. British Journal of Educational Technology, 38(1), 106-115.

Critz, C. M., \& Knight, D. (2013). Using the flipped classroom in graduate nursing education. Nurse Educator, 38(5), 210-213. doi.org/10.1097/NNE.0b013e3182a0e56a

Davies, R., Dean, D., \& Ball, N. (2013). Flipping the classroom and instructional technology integration in a college-level information systems spreadsheet course. Education Technology Research and Development, 61(4), 563-580. doi.org/10.1007/s11423-013-9305-6

Deslauriers, L., Schelew, E., \& Wieman, C. (2011). Improved learning in a large-enrolment physics class. Science, 332(6031), 862-864. doi.org/10.1126/science.1201783DeVaney, T. A. (2010). Anxiety and attitude of graduate students in on-campus vs. online statistics courses. Journal of Statistics Education, 18(1), Retrieved from http://www.amstat.org/publications/jse/v18n1/devaney.pdf

Ferguson, C. (2002). Using the revised taxonomy to plan and deliver team-taught, integrated, thematic units. Journal of Theory into Practice, 41(4), 238-243. doi.org/10.1207/s15430421tip4104_6

Fulton, K. (2012). Upside down and inside out: Flip your classroom to improve student learning. Learning \& Leading with Technology, 39(8), 12-17.

Garfield, J. (1993). Teaching statistics using small-group cooperative learning. Journal of Statistics Education, 1(1). Retrieved from http://www.amstat.org/publications/jse/v1n1/garfield.html

Garfield, J. (2013). Cooperative learning revisited: From an instructional method to a way of

life. Journal of Statistics Education, 21(2). Retrieved from http://www.amstat.org/publications/jse/v21n2/garfield.pdf

Garrison, D. R., \& Kanuka, H. (2004). Blended learning: Uncovering its transformative potential in higher education. The Internet and Higher Education, 7(2), 95-105. doi.org/10.1016/j.iheduc.2004.02.001

George-Palilonis, J., \& Filak, V. (2009). Blended learning in the visual communications classroom: Student reflections on a multimedia course. Electronic Journal of e-Learning, 7(3), 247-256.

Gillies, R. M., \& Boyle, M. (2010). Teachers' reflections on cooperative learning: Issues in implementation. Teaching and Teacher Education, 26(4), 933-940. doi.org/10.1016/j.tate.2009.10.034 
Gillies, R. M., \& Boyle, M. (2011). Teachers’ reflections of cooperative learning (CL): A two-year follow-up. Teaching Education, 22(1), 63-78. doi.org/10.1080/10476210.2010.538045

Giraud, G. (1997). Cooperative learning and statistics instruction. Journal of Statistics Education, 5(3). Retrieved August 2, 2013, from http://www.amstat.org/publications/jse/v5n3/giraud.html

Graham, C. R., \& Allen, S. (2009). Designing blended learning environments. In P. L. Rogers, G. A. Berg, J. V. Boettecher, C. Howard, L. Justice, \& K. Schenk (Eds.), Encyclopedia of distance learning (Vol. 2, pp. 562-570). Hershey, PA: Idea Group Inc.

Graham, C. R., Woodfield, W., \& Harrison, J. B. (2013). A framework for institutional adoption and implementation of blended learning in higher education. The Internet and Higher Education, 18, 4-14. doi.org/10.1016/j.iheduc.2012.09.003

Halverson, L. R., Graham, C. R., Spring, K. J., Drysdale, J. S., \& Henrie, C. R. (2014). A thematic analysis of the most highly cited scholarship in the first decade of blended learning research. The Internet and Higher Education, 20, 20-34. doi.org/10.1016/j.iheduc.2013.09.004

Herreid, C.F., \& Schiller, N.A. (2013). Case studies and the flipped classroom. Journal of College Science Teaching, 42(5), 62-66.

Jones, N., \& Lau, A. M. S. (2010). Blending learning: Widening participation in higher education. Innovations in Education and Teaching International, 47(4), 405-416. doi.org/10.1080/14703297.2010.518424

Kalof, L. (1998). Understanding the social construction of environmental concern. Human Ecology Review, 4(2), 101-105.

Keeler, C. M., \& Steinhorst, R. K. (1995). Using small groups to promote active learning in the Introductory Statistics course: A report from the field. Journal of Statistics Education, 3(2). Retrieved from http://www.amstat.org/publications/jse/v3n2/keeler.html

Kennedy, D. M., \& Fox, B. (2013). 'Digital natives': An Asian perspective for using learning technologies. International Journal of Education and Development using Information and Communication Technology, 9(1), 64-79.

Krathwohl, D. R. (2002). A revision of Bloom's Taxonomy: An overview. Journal of Theory into Practice, 41(4), 212-218. doi.org/10.1207/s15430421tip4104_2

Krause, U. M., Stark, R., \& Mandl, H. (2009). The effects of cooperative learning and feedback on eLearning in statistics. Learning and Instruction, 19(2), 158-170. doi.org/10.1016/j.learninstruc.2008.03.003

Lim, C. P., Zhao, Y., Tondeur, J., Chai, C. S., \& Tsai, C. C. (2013). Bridging the gap: Technology trends and use of technology in schools. Educational Technology \& Society, 16(2), 59-68.

Lim, D. H., \& Morris, M. L. (2009). Learner and instructional factors influencing learning outcomes within a blended learning environment. Educational Technology \& Society, 12(4), 282-293.

Magel, R. C. (1998). Using cooperative learning in a large introductory statistics class. Journal of Statistics Education, 6(3). Retrieved from http://www.amstat.org/publications/jse/v6n3/magel.html

Mayer, R. E. (2002). Rote versus meaningful learning. Journal of Theory into Practice, 41(4), 226-232. doi.org/10.1207/s15430421tip4104_4

McKeown, B., \& Thomas, D. (1988).Q Methodology. Newbury Park: Sage Publications.

McLaughlin, J. E., Griffin, L. M., Esserman, D. A., Davidson, C., Glatt, D. M., Roth, M. T., Mumper, R. J. (2013). Pharmacy student engagement, performance, and perception in a flipped satellite classroom. American Journal of Pharmaceutical Education, 77(9), Article 196.

doi: 10.5688/ajpe779196

McLaughlin, J. E., Roth, M. T., Glatt, D. M., Gharkholonarehe, N., Davidson, C. A., Griffin, L. M., . . Mumper, R. J. (2014). The flipped classroom: A course design to foster learning and engagement in health professions education. Academic Medicine, 89(2), 236-243. doi.org/10.1097/ACM.0000000000000086

Missildine, K., Fountain, R., Summers, L., \& Gosselin, K. (2013). Flipping the classroom to improve student performance and satisfaction. Journal of Nursing Education, 52(10), 597-599. doi.org/10.3928/01484834-20130919-03

Onwuegbuzie, A. J., \& Wilson, V. A. (2003). Statistics anxiety: Nature, etiology, antecedents, effects, and treatments-a comprehensive review of the literature. Teaching in Higher Education, 8(2), 195209. doi.org/10.1080/1356251032000052447

Osguthorpe, R. T., \& Graham, C. R. (2003). Blended learning systems: Definitions and directions. Quarterly Review of Distance Education, 4(3), 227-234. 
Pierce, R., \& Fox, J. (2012). Vodcasts and active-learning exercises in a "flipped classroom” model of a renal pharmacotherapy module. American Journal of Pharmaceutical Education, 76(10), Article 196. doi: 10.5688/ajpe7610196

Pintrich, P. R. (2002).The role of metacognitive knowledge in learning, teaching, and assessing. Journal of Theory into Practice, 41(4), 219-225. doi.org/10.1207/s15430421tip4104_3

Prensky, M. (2001a). Digital natives, digital immigrants. On the Horizon, 9(5), 1-6. doi.org/10.1108/10748120110424816

Prensky, M. (2001b). Digital natives, digital immigrants, part 2: Do they really think differently? On the Horizon, 9(6), 1-6. doi.org/10.1108/10748120110424843

Rushby, N. (2013). The future of learning technology: Some tentative predictions. Educational Technology \& Society, 16(2), 52-58.

Sankey, M. D., \& Hunt, L. (2013). Using technology to enable flipped classrooms whilst sustaining sound pedagogy. In H. Carter, M. Gosper, \& J. Hedberg (Eds.), Electric dreams. Proceedings ascilite 2013 Sydney (pp.785-795). Sydney, Australia: Macquarie University.

Schmid, K. K. (2013). Virtual discussion for real understanding: The use of an online discussion board in an introductory biostatistics course. Technology Innovations in Statistics Education, 7(1). Retrieved from: http://www.escholarship.org/uc/item/89q3489f

Shih, R. C. (2011). Can Web 2.0 technology assist college students in learning English writing? Integrating Facebook and peer assessment with blended learning. In J. Waycott \& J. Sheard (Eds), Assessing students' Web 2.0 activities in higher education. Australasian Journal of Educational Technology, 27 (Special issue, 5), 829-845. Retrieved from: http://www.ascilite.org.au/ajet/ajet27/shih.html

Shinebourne, P., \& Adams, M. (2007). Q-methodology as a phenomenological research method. Existential Analysis, 18(1), 103-116.

Slavin, R. E. (1995). Cooperative learning: Theory, research and practice. Boston, MA: Allyn and Bacon.

Steinhorst, R. K., \& Keeler, C. W. (1995). Developing material for introductory statistics courses from a conceptual, active learning viewpoint. Journal of Statistics Education, 3(3). Retrieved from http://www.amstat.org/publications/jse/v3n3/Steinhorst.html

Stellefson, M., Hanik, B., Chaney, J. D, \& Tennant, B. (2012). Analysis of eHealth search perspectives among female college students in the health professions using Q methodology. Journal of Medical Internet Research, 4(2), e60. doi: 10.2196/jmir.1969

Strayer, J. (2012). How learning in an inverted classroom influences cooperation, innovation and task orientation. Learning Environments Research, 15(2), 171-193. doi.org/10.1007/s10984-012-9108-4

Tapscott, D. (1999). Educating the Net Generation. Educational Leadership, 56(5), 6-11.

Thurston, A., Topping, K.J., Tolmie, A.K., Christie, D., Karagiannidou, E., \& Murray, P. (2010).Cooperative learning in science: Follow-up from primary to high school. International Journal of Science Education, 32(4), 501-522. doi.org/10.1080/09500690902721673

Tselios, N., Daskalakis, S., \& Papadopoulou, M. (2011). Assessing the acceptance of a blended learning university course. Educational Technology \& Society, 14(2), 224-235.

Tune, J. D., Sturek, M., \& Basile, D. P. (2013). Flipped classroom model improves graduate student performance in cardiovascular, respiratory, and renal physiology. Advances in Physiology Education, 37(4), 316-320. doi.org/10.1152/advan.00091.2013

Valenta, A. L., \& Wigger, U. (1997). Q-methodology: Definition and application in health care informatics. Journal of the American Medical Informatics Association, 4(6), 501-510. doi.org/10.1136/jamia.1997.0040501

von Konsky, B. R., Ivins, J., \& Gribble, S. J. (2009). Lecture attendance and web based lecture technologies: A comparison of student perceptions and usage patterns. Australasian Journal of Educational Technology, 25(4), 581-595. Retrieved from: http://www.ascilite.org.au/ajet/ajet25/vonkonsky.html

Vygotsky, L. S. (1978). Mind in society. Cambridge, MA: Harvard University Press.

Wei, C. W., Chen, N. S., \& Kinshuk. (2012). A model for social presence in online classrooms. Educational Technology Research and Development, 60(3), 529-545. doi.org/10.1007/s11423-0129234-9

Williams, A. S. (2010). Statistics anxiety and instructor immediacy. Journal of Statistics Education, 18(2). Retrieved from http://www.amstat.org/publications/jse/v18n2/williams.pdf 
Zhang, Y. (2013). Power distance in online learning: Experience of Chinese learners in U.S. higher education. The International Review of Research in Open and Distance Learning, 14(4). Retrieved from http://www.irrodl.org/index.php/irrodl/article/view/1557/2633

Corresponding author: Nian-Shing Chen, nschen@mis.nsysu.edu.tw

Australasian Journal of Educational Technology (c) 2015.

Please cite as: Chen, L., Chen, T-L., \& Chen, N-S. (2015). Students' perspectives of using cooperative learning in a flipped statistics classroom. Australasian Journal of Educational Technology, 31(6), 621-640. 
Appendix A

\section{Sorting Answer Sheet}

INSTRUCTIONS: Please sort the 30 statements and provide the following information.

MY OPINION OF A FLIPPED CLASSROOM

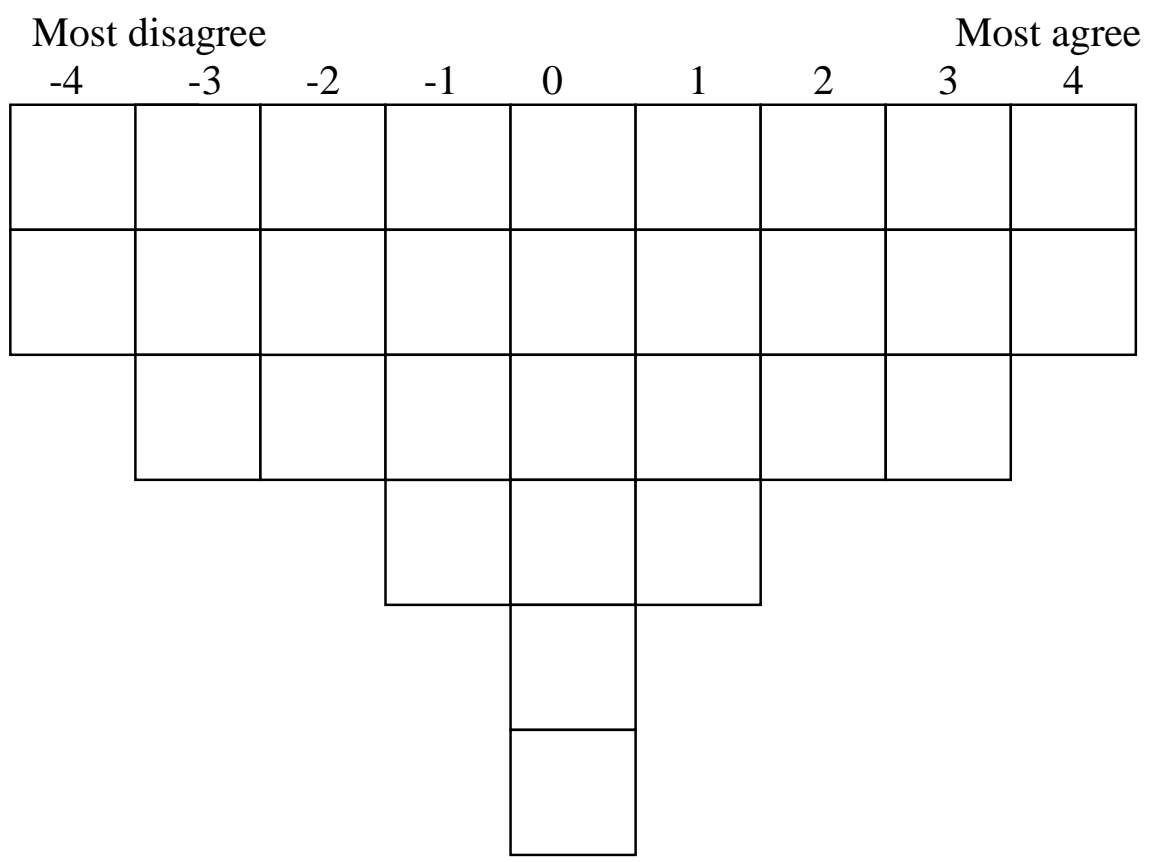




\section{Appendix B}

\section{Sorting Instructions}

Please sort the 30 statements according to those with which you most agree $(+4)$ to those with which you most disagree (-4). Please read the "sorting instructions" first, and then, write your answers on the "sorting answer sheet." The steps are as follows:

1. Three forms will be distributed to you. These include (1) participants’ opinion statements, (2) sorting instructions, and (3) sorting answer sheet.

2. Read all 30 Q-statements on "participants' opinion statements” and the "sorting instructions” first.

3. Sort the 30 statements into two columns: Important vs. Not important. Please write your answers in the boxes below.

\begin{tabular}{|c|c|}
\hline Not important & Important \\
\hline & \\
& \\
& \\
\hline
\end{tabular}

It is not necessary to have an equal number of statements in each column. If you find there are not enough items in the "important" column fFor steps 4, 6, 8, and 10, you can proceed further and choose items from the "not important" column instead. For steps 5, 7, 9, and 11, if you find there are not enough items on the "not important" pile, you can proceed further and choose items from the "important" column instead.

4. Select two items from the "important" column that are most like your position. Write the two item numbers vertically on the right hand side of the sorting answer sheet. These should be placed under the " +4 " marker. The order of the items under the markers is not important.

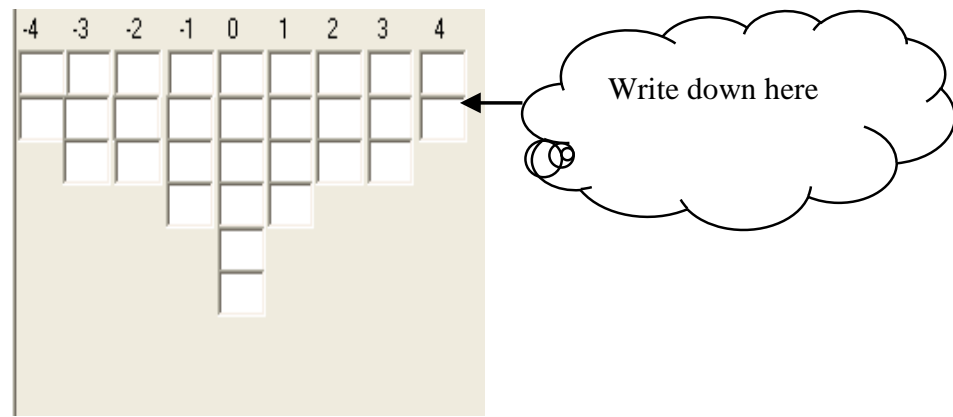

5. Select two items from the "not important" column, which are most unlike your position. Write the two item numbers vertically on the left hand side of the sorting answer sheet. Place these under the " -4 " marker. Again, the specific order of the items under the markers is not important.

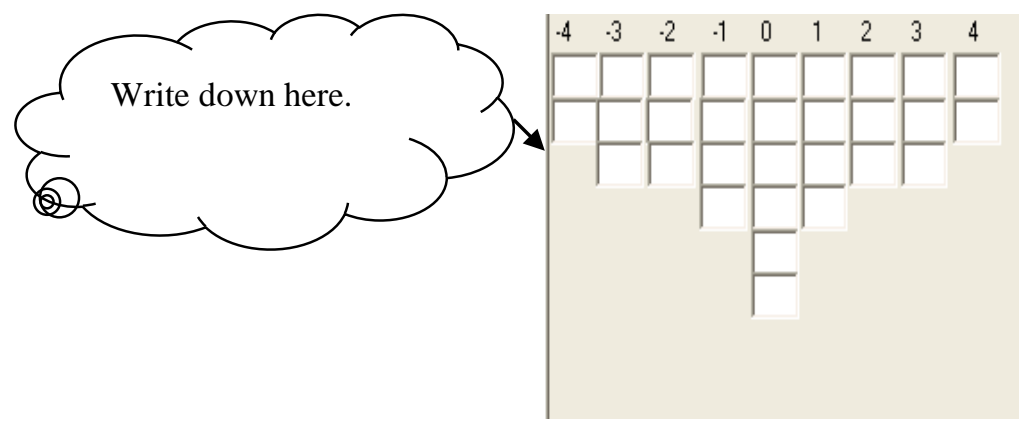


6. Select three items from the remaining "important" column that are more like your position than the remaining statements, but which are not as significant as the two already selected (i.e., those placed under "+4"). Write the three item numbers vertically on the right hand side of the sorting answer sheet. These should be placed under the "+3" marker.

7. Select three items from the remaining "not important" column that are more unlike your position than the remaining statements, but which are not as significant as the two already selected (i.e., those placed under "-4”). Write the three item numbers vertically on the left hand side of the sorting answer sheet. These should be placed under the "-3" marker.

8. Select three items from the remaining "important" column and write the three item numbers vertically on the right hand side of the sorting answer sheet. Place these under the "+2" marker.

9. Select three items from the remaining "not important" column and write the three item numbers vertically on the left hand side of the sorting answer sheet. Place these under the "-2" marker.

10. Select four items from the remaining "important" column and write the four item numbers vertically on the right hand side of the sorting answer sheet. Place these under the " +1 " marker.

11. Select four items from the remaining "not important" column and write the four item numbers vertically on the left hand side of the sorting answer sheet. Place these under the "-1" marker.

12. Write down the remaining six items vertically in the middle column, and place them under the " 0 " marker.

13. Review the Q-sort arrangement. Please feel free to change the order of the Q-sort and to make sure it is written in the proper place. An example is as follows:

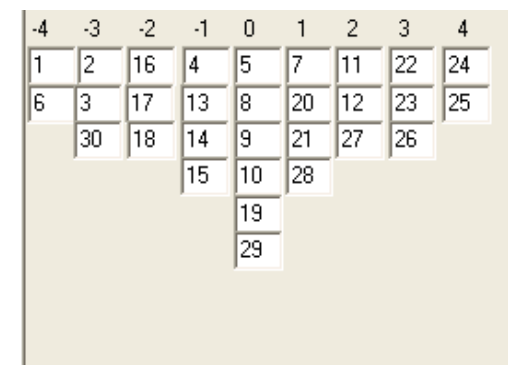

14. Return the questionnaire to the interviewer. 